See Article page 1705.

\section{Commentary: Go big or stay home?}

\section{Sitaram Chilakamarry, MD, ${ }^{a}$ and Daniel J. Boffa, $\mathrm{MD}^{\mathrm{b}}$}

Preventing patients from undergoing complex surgical procedures in environments that are not adequately prepared (ie, lack of experience, specialty-trained personnel, or critical resources) to perform the procedure safely just makes sense. The economics of regionalization ${ }^{1}$ seem intuitive because favorable outcomes appear to be far more costeffective than recovery fraught with adversity. However, investment and return are quite different based on the vantage point from which they are measured.

Insisting that all patients undergo surgery at high-volume hospitals is imperfect because not all high-volume hospitals are safe, and not all low-volume hospitals are unsafe. Chiu and colleagues ${ }^{2}$ found that if one were to instead regionalize by safety performance (ie, a hospital's ability to achieve low risk-adjusted mortality) rather than volume, one could save twice as many lives by moving half as many patients and have far more destination hospitals (the safest category) to which to send patients. Almost certainly the financial gains will in some way correlate with the efficiency of regionalization (ie, how many people need to move to save a single life).

The financial influence of regionalization at any scale feels like a potential win, and yet this is highly dependent upon the perspective. From the hospital and surgeon perspective at destination hospitals, caring for additional patients (those coming from less-safe hospitals) could be financially favorable. However, depending on the payer mix, some of the more complex surgical procedures have modest margins in terms of hospital or surgeon fees. In addition, if complex patients consume a disproportionate number of resources, this may restrict destination hospitals

\footnotetext{
From the ${ }^{a}$ Department of Surgery, University of Texas Southwestern Medical Center, Dallas, Tex; and 'bection of Thoracic Surgery, Department of Surgery, Yale University School of Medicine, New Haven, Conn.

Disclosures: The authors reported no conflicts of interest.

The Journal policy requires editors and reviewers to disclose conflicts of interest and to decline handling or reviewing manuscripts for which they may have a conflict of interest. The editors and reviewers of this article have no conflicts of interest.

Received for publication Dec 18, 2020; revisions received Dec 18, 2020; accepted for publication Dec 21, 2020; available ahead of print Dec 26, 2020.

Address for reprints: Daniel J. Boffa, MD, Section of Thoracic Surgery, Department of Surgery, Yale University School of Medicine, PO Box 208062, New Haven, CT 06520-8062 (E-mail: Daniel.boffa@yale.edu).

J Thorac Cardiovasc Surg 2021;161:1711-2

$0022-5223 / \$ 36.00$

Copyright (c) 2021 by The American Association for Thoracic Surgery

https://doi.org/10.1016/j.jtcvs.2020.12.083
}

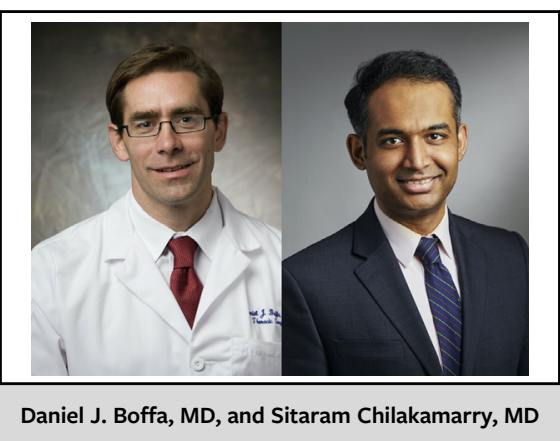

\section{CENTRAL MESSAGE \\ The economy of regionalization will have disproportionate effects on the players involved, and remains to be fully understood. The metric used for this change needs refinement beyond just quantity.}

from performing higher margin (ie, lower risk) procedures, which may be disadvantageous.

From the hospital (and surgeon) away from which patients are regionalized, there is a reduction in clinical activity. However, avoiding low-frequency, high-complication procedures may ultimately be advantageous, particularly with bundled payments.

The patient finances are more challenging because they are completely dependent on the value a patient places on the enhanced safety. For example, if a patient is indifferent regarding a surgical mortality rate of 3\% versus $9 \%$, then the additional cost and inconvenience of travel to regionalize may not be worth much. This may also depend on how this is presented (eg, "triple the chances of dying from surgery," or "91\% chance of surviving vs 97\%"). A hidden cost factor to consider is travel for subsequent care (eg, care for cancer recurrence, which occurs in $20 \%$ $50 \%$ of non-small cell lung cancer). This is especially true for low-population-density areas, which tend to be farther away from regional centers. These out-of-pocket expenses can be prohibitive for patients. Resio and colleagues ${ }^{3}$ note that financial considerations are the most common hindrance for travel to regional centers.

The elephant in the room is the private payer, and his or her ability and/or willingness to pay for care at regional centers, especially if they happen to be outof-network. Another factor to be considered is the average cost at a given facility. If a facility's average 
cost is high to begin with (because of higher wages, use of more resources, or high price of materials), then there may not be enough economic savings despite increased volume via regionalization. ${ }^{4}$

In addition to economics, the ethos of regionalization should factor in patient preferences: What if a patient seeks to remain at the local center not just for convenience, but also because of an established relationship with his or her provider? There also needs to be foresight on how trainees' learning experiences might get skewed on either end of the equation, and how best to ensure balance.

Finally, there is a real possibility that regionalization of complex care may decrease access to care (eg, cuttingedge treatments may become available only at the regional centers, making it difficult for rural patients to access them).
For some patients, the barriers to regionalization force a decision between care in the less-safe environment and going without the complex surgical procedure, a choice that also carries a distinct set of financial implications.

\section{References}

1. Subramanian MP, Yang Z, Chang S-H, Puri V. Regionalization for thoracic surgery: economic implications of regionalization in the United States. J Thorac Cardiovasc Surg. 2021;161:1705-9.

2. Chiu AS, Arnold BN, Hoag JR, et al. Quality versus quantity: the potential impact of public reporting of hospital safety for complex cancer surgery. Ann Surg. 2019; 270:281-7.

3. Resio BJ, Chiu AS, Hoag JR, Brown LB, White M, Omar A, et al. Motivators, barriers, and facilitators to traveling to the safest hospitals in the United States for complex cancer surgery. JAMA Netw Open. 2018;1:e184595.

4. Menke TJ, Wray NP. When does regionalization of expensive medical care save money? Health Serv Manage Res. 2001;14:116-24. 